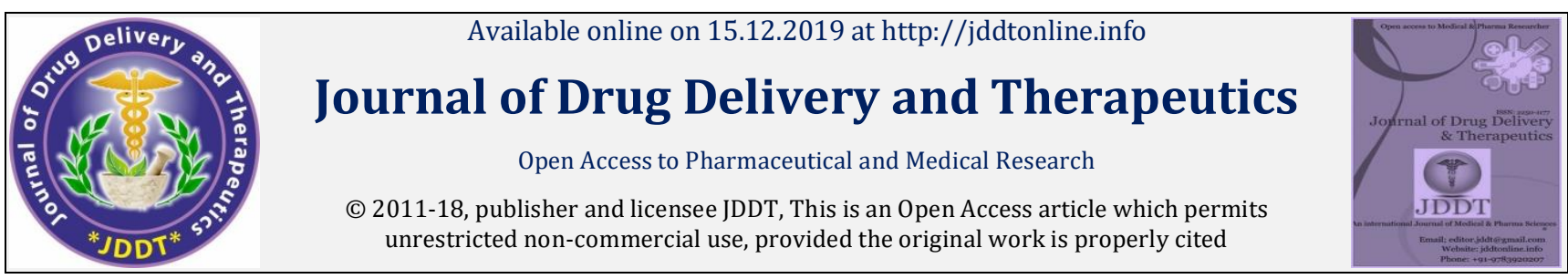

Open 2 Access

Research Article

\title{
In Vivo and In Vitro Antidiabetic Activity of Hydroalcoholic Extract of Dactylorhiza Hatagirea Roots: An Evaluation of Possible Phytoconstituents
}

\author{
Rashmi Choukarya*, Ashish Choursia, Jagdish Rathi \\ NRI Institute of Pharmaceutical Sciences, Bhopal (M.P.), India
}

\begin{abstract}
Diabetes mellitus is one of the most common endocrine disorder which causes microvascular and macrovascular complications. Several synthetic drugs used to treat diabetes have adverse effects on prolonged usage. This has given the impetus to the search for alternative medicines with no or less side effects. The plants of Orchidaceae family have displayed antimicrobial, anti-inflammatory, antioxidant, anticancer and antidiabetic activity. However, their antidiabetic properties are yet to be explored. This study sought to evaluate the antidiabetic potentials of hydroalcoholic extract of root of Dactylorhiza hatagirea (D. hatagirea) in diabetic rats. Qualitative analysis of various phytochemical constituents and quantitative analysis of total flavonoids were determined by the well-known test protocol available in the literature and quercetin was detected in hydroalcoholic extract of root of $D$. hatagirea under study by using RP-HPLC analysis. Percentage inhibition of $\alpha$ amylase activity by $D$. hatagirea root extract was estimated with acarbose as the positive control, $D$. hatagirea extract show dose dependent activity. IC 50 value of acarbose and extract was found to 35.33 and $224.45 \mu \mathrm{g} / \mathrm{ml}$ respectively. Diabetes was induced in wistar albino rats by administration of alloxan monohydrate $(120 \mathrm{mg} / \mathrm{kg}$; i.p.). The of hydroalcoholic extract of $D$. hatagirea at a dose of 100 and $200 \mathrm{mg} / \mathrm{kg}$ body weight was administrated at a single dose per day to diabetes-induced rats for a period of 15 day. The effect of hydroalcoholic extract of $D$. hatagirea root on blood glucose, total cholesterol (TR), triglycerides (TG), total protein and body weight were measured in the diabetic rats. The effect of hydroalcoholic extract of $D$. hatagirea root elicited significant reduction in blood glucose $(p<0.001),(p<0.01)$, lipid parameters (TC, TG, total protein) $(p<0.01)$ and significantly increased body weight at the dose of $200 \mathrm{mg} / \mathrm{kg}$ when compared with the diabetic-induced control. For future studies, phytochemcials responsible for various activities can be isolated and modified for pharmacological purpose.This study, therefore, justifies the use of the plant in the treatment of diabetes mellitus.
\end{abstract}

Keywords: Dactylorhiza hatagirea, Phytochemical profile, Quercetin, RP-HPLC, In Vivo and In Vitro Antidiabetic Activity

Article Info: Received 10 Oct 2019; Review Completed 19 Nov 2019; Accepted 28 Nov 2019; Available online 15 Dec 2019

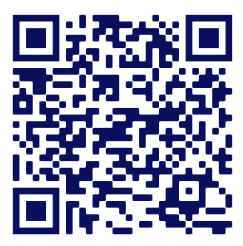

\section{Cite this article as:}

Choukarya R, Choursia A, Rathi J, In Vivo and In Vitro Antidiabetic Activity of Hydroalcoholic Extract of Dactylorhiza Hatagirea Roots: An Evaluation of Possible Phytoconstituents, Journal of Drug Delivery and Therapeutics. 2019; 9(6s):76-81 http://dx.doi.org/10.22270/jddt.v9i6-s.3752

*Address for Correspondence:

Rashmi Choukarya, NRI Institute of Pharmaceutical Sciences, Bhopal (M.P.), Idia

\section{INTRODUCTION}

Diabetes is characterized by hyperglycemia, altered lipids, carbohydrates and proteins metabolism which affect the patient quality of life in terms of social, psychological wellbeing as well as physical ill health ${ }^{1,2}$. Two forms of diabetes (Types 1 and 2) differ in their pathogenesis, but both have hyperglycemia as a common hall mark. In type 2 diabetes, hyperglycemia caused due to impairment in insulin secretion combined with or without impairment of insulin action $^{3}$. The World Health Organization reported that worldwide global population is in the midst of a diabetes epidemic. The people in Southeast Asia and Western Pacific are being under greater risk and the majority of patients have type 2 diabetes. Insulin resistance typically precedes the onset of type 2 diabetes and is commonly accompanied by other cardiovascular risk factors such as dyslipidemia, hypertension and prothrombotic factors ${ }^{4}$.Diabetes-related cardiovascular complications occur due to altered lipoprotein metabolism-mediated atherosclerosis and diabetics are 2 to 4 times more likely to suffer from stroke ${ }^{5}$. Although different classes of drugs are available to control type 2 diabetes, still it is a challenging task to bring a better molecule which is devoid of undesirable adverse effects than existing drugs. In Indian traditional medicine systems, the number of medicinal plants has been used since ancient time to effectively treat diabetes ${ }^{6}$. Multiple mechanisms, due to many phytoconstituents were documented for the antidiabetic activity of medicinal plants. Therefore, documenting the efficacy of antidiabetic medicinal plants has been increased and their characterizations of chemical constituents are focused in drug discovery programmes to bring a better lead molecule to treat diabetes?. The genus Dactylorhiza (Orchidaceae) is represented by approximately 
75 species, distributed in most parts of Northern temperate zone. D. hatagirea (D. Don) Soo is a perennial orchid, native to the Himalayan region ${ }^{8}$. This species is distributed in India, Pakistan, Afghanistan, Nepal, Tibet and Bhutan. In India, it is distributed in Jammu and Kashmir ${ }^{9}$, Uttarakhand ${ }^{10-12}$ and Himachal Pradesh ${ }^{13}$. D. hatagirea is also a high-value medicinal orchid used in Ayurveda, Siddha and Unani medicine ${ }^{14}$. It is widely used to cure various diseases including dysentery, diarrhea, chronic fever, cough, stomachache, wounds, cuts, burns, fractures, and general weakness. The rhizomes of $D$. hatagirea contain bitter substance, glucoside mucilage, albumen, starch, a trace of volatile oil and $a^{15}$. Chemically, dactylorhins $A$ to $E$, dactyloses A and B, lipids, and so on are found as major constituents. The tubers of this species yield a high quality salep which is used as a tonic to increase immunity (immunomodulator) and as a vajikaran drug (aphrodisiac); it increases sexual performance as well as serving as a nervine tonic ${ }^{16}$. Recently herbal health beverages have also been developed from this species ${ }^{17}$. Tubers of this species are supposed as a potent medicine in Leucorrhea in Traditional System of Medicine (TSM). Hence, there is a need for a more effective drug with lower side effects. Therefore, the present study was aimed to investigate in vitro and vivo antidiabetic activity of hydroalcoholic extracts of $D$. hatagirea in type 2 diabetic rats. The phytoconstituents (biomarkers) present in extract were characterized by highperformance liquid chromatography (HPLC) analysis.

\section{MATERIALS AND METHODS}

\section{Collection of plant material}

Fresh root plant material of $D$. hatagirea was collected from local area of Bhopal (M.P.) in the month of August, 2019. The plant material were washed thoroughly with normal tap water followed by sterile distill water. Then plant material was dried under shaded condition at room temperature. Fresh plant materials of $D$. hatagirea were crushed to powder using grinding machine. Powder was stored at $4{ }^{\circ} \mathrm{C}$ in tight air container bottle.

\section{Chemical reagents}

Alloxan (Central Drug House Pvt. Ltd., India), Glibenclamide tablets (Daonil; Aventis Pharma. Ltd., India) were procured from the authorized distributor of the company. All the chemicals used in this study were obtained from Hi Media Laboratories Pvt. Ltd. (Mumbai, India), Sigma Aldrich Chemical Co. (Milwaukee, WI, USA), SD Fine-Chem Chem. Ltd. (Mumbai, India) and SRL Pvt. Ltd. (Mumbai, India) Quercetin was kindly provided by Scan Research Laboratories, Bhopal (India). Methanol and acetonitrile were of HPLC grade and purchased from Merck Ltd, New Delhi, India. All other chemicals and solvents used were of HPLC and analytical grade.

\section{Extraction procedure}

The maceration method was followed for the extraction. 42 gm powder of dried plant material was added into $100 \mathrm{ml}$ of $70 \%$ methanol in an Erlenmeyer flask (250 ml capacity) and resulting mixture was vortexed well. The maceration process was carried out in shaker incubator at with $50 \mathrm{rpm}$ for $48-72 \mathrm{hrs}$. After this process, the extracts were filtered dried extract was stored in refrigerator for their future use in phytochemical analysis.

\section{Qualitative phytochemical analysis of plant extract}

The D. hatagirea extracts obtained was subjected to the preliminary phytochemical analysis following standard methods by Khandelwal and Kokate ${ }^{18,19}$. The extract was screened to identify the presence or absence of various active principles like phenolic compounds, carbohydrates, flavonoids, glycosides, saponins, alkaloids, fats or fixed oils, protein and amino acid and tannins.

\section{Total flavonoids determination}

The total flavonoid content was determined using the method of Olufunmiso et al $20.1 \mathrm{ml}$ of $2 \% \mathrm{AlCl}_{3}$ methanolic solution was added to $3 \mathrm{ml}$ of extract or standard and allowed to stand for $15 \mathrm{~min}$ at room temperature; the absorbance of the reaction mixture was measured at $420 \mathrm{~nm}$ using UV/visible spectrophotometer The content of flavonoids was calculated using standard graph of quercetin and the results were expressed as quercetin equivalent (mg/100mg).

\section{Quantification of flavonoid compounds by HPLC technique}

For HPLC investigation of flavonoid compounds the hydroalcoholic extracts of $D$. hatagirea root under study were used as a preliminary assessment of various compounds. The HPLC apparatus used for analysis was composed of a waters equipped with a UV dual detector and generated data were analyzed using Waters Ace software. For chromatographic separation Thermo C18 column (250 X $4.6 \mathrm{~mm}, 5 \mu \mathrm{m})$ was applied. The chromatographic analysis was performed at ambient temperature on a RP-C18 analytical column with a mobile phase composed of Acetonitrile: Methanol (50:50 v/v) and was isocratically eluted at a flow rate of $1 \mathrm{ml} / \mathrm{min}$. A small sample volume of $20 \mu \mathrm{l}$ was used for each sample run, being injected into the HPLC system. The chromatogram was monitored with UV detection at a wavelength of $256 \mathrm{~nm}$. Sample volume $(20 \mu \mathrm{l})$ and analysis time was $10 \mathrm{~min}$ for both, standards and samples used for analysis. A quercetin was used as standards. A thermospectronic model of Labindia $3000+U V / V I S$ Spectrophotometer with $1 \mathrm{~cm}$. matched quartz cells were used for determination of $\lambda$ max. The sample solution was chromatographed and a concentration of quercetin in extract sample was found out using regression equation.

\section{In vitro anti diabetic activity of extract}

\section{Inhibition of alpha amylase enzyme}

A total of $500 \mu \mathrm{l}$ of test samples and standard drug (10 $50 \mu \mathrm{g} / \mathrm{ml}$ ) were added to $500 \mu \mathrm{l}$ of $0.20 \mathrm{mM}$ phosphate buffer ( $\mathrm{pH} 6.9)$ containing $\alpha$-amylase $(0.5 \mathrm{mg} / \mathrm{ml})$ solution and were incubated at $25^{\circ} \mathrm{C}$ for $10 \mathrm{~min}$. After these, $500 \mu \mathrm{l}$ of a $1 \%$ starch solution in $0.02 \mathrm{M}$ sodium phosphate buffer $(\mathrm{pH}$ 6.9) was added to each tube. The reaction mixtures were then incubated at $25^{\circ} \mathrm{C}$ for $10 \mathrm{~min}$. The reaction was stopped with $1.0 \mathrm{ml}$ of 3,5 dinitrosalicylic acid colour reagent. The test tubes were then incubated in a boiling water bath for 5 min, cooled to room temperature. The reaction mixture was then diluted after adding $10 \mathrm{ml}$ distilled water and absorbance was measured at $540 \mathrm{~nm}$. Control represent $100 \%$ enzyme activity and were conducted in similar way by replacing extract with vehicle.

\section{In vivo anti diabetic activity of extract}

\section{Animals}

Wistar rats (180-230 g) were group housed $(n=6)$ under a standard $12 \mathrm{~h}$ light/dark cycle and controlled conditions of temperature and humidity $\left(25 \pm 2{ }^{\circ} \mathrm{C}, 55-65 \%\right)$. Rats received standard rodent chow and water ad libitum. Rats were acclimatized to laboratory conditions for 7 days before carrying out the experiments. All the experiments were carried in a noise-free room between 08.00 to $15.00 \mathrm{~h}$. Separate group $(n=6)$ of rats was used for each set of 
experiments. The animal studies were approved by the Institutional Animal Ethics Committee (IAEC), constituted for the purpose of control and supervision of experimental animals by Ministry of Environment and Forests, Government of India, New Delhi, India.

\section{Acute oral toxicity}

Acute toxicity study of the prepared extracts was carried out according to the Organization for Economic Co-Operation and Development (OECD) Guidelines-42321 the animals were fasted for $4 \mathrm{~h}$, but allowed free access to water throughout. As per the OECD recommendations, the starting dose level should be that which is most likely to produce mortality in some of the dosed animals; and when there is no information available on a substance to be tested in this regard; for animal welfare reasons, The dose level to be used as the starting dose is selected from one of three fixed levels $50,100,150,300$ and $2000 \mathrm{mg} / \mathrm{kg}$ body weight orally for 4 days of six groups of rats $(n=6)$. Acute toxicity was determined as per reported method 22 .

\section{Induction of experimental diabetes in rats}

After fasting, diabetes was induced by a single intraperitoneal injection of $120 \mathrm{mg} / \mathrm{kg}$ body weight of 'Alloxan monohydrate' in distilled water. The animals were allowed to drink $5 \%$ glucose solution overnight to overcome the drug-induced hypoglycaemia. These animals were tested for diabetes after 15 days and animals with blood glucose (fasting) were selected for experimentation ${ }^{23}$.

\section{Experimental protocol}

Five groups of rats were employed in the present study and each group contains six animals, as follows

Group I: Rats served as normal-control and received the vehicle $(0.5 \mathrm{ml}$ distilled water/day/rat)

Group II: Rats served as diabetic-control and received the vehicle $(0.5 \mathrm{ml}$ distilled water/day/rat)
Group III: Rats (diabetic) were administered Dactylorhiza hatagirea (100 mg/kg p.o.) for 15 days.

Group IV: Rats (diabetic) were administered Dactylorhiza hatagirea (200 mg/kg p.o.) for 15 days.

Group V: Rats (diabetic) were administered Glibenclamide $(600 \mu \mathrm{g} / \mathrm{kg}$ p.o.) for 15 days.

\section{Bioassay}

On 15th day of treatment, blood samples were collected by retro-orbital plexus puncture method under mild ether anesthesia and serum was separated by centrifugation. Serum glucose, total protein, cholesterol (TC) and total triglyceride (TG) levels were evaluated using a commercial $\mathrm{kit}^{24}$. Body weights of rats were taken before and after treatment 25 .

\section{Statistical analysis}

Results were expressed as mean \pm SEM. Data were analyzed with one way ANOVA for the comparison between groups, followed by Tukey as a post hoc test.

\section{RESULTS AND DISCUSSIONS}

The crude extracts so obtained after maceration extraction process was concentrated on water bath by evaporation the solvents completely to obtain the actual yield of extraction. The yield of hydroalcoholic extracts was found to be 8.556 $\%$. The results of qualitative phytochemical analysis of the crude powder of root of $D$. hatagirea were shown in Table 1. Hydroalcoholic extracts of $D$. hatagirea showed the presence of flavonoids, carbohydrate and saponins. The content of total flavonoid compounds (TFC) was expressed as $\mathrm{mg} / 100 \mathrm{mg}$ of quercetin equivalent of dry extract sample using the equation obtained from the calibration curve: $\mathbf{Y}=$ $\mathbf{0 . 0 6 X + 0 . 0 1 9}, R^{2}=0.999$, where $X$ is the quercetin equivalent $(\mathrm{QE})$ and $\mathrm{Y}$ is the absorbance Table 2.

Table 1 Results of phytochemical screening of $D$. hatagirea

\begin{tabular}{|c|l|l|l|c|}
\hline S. No. & \multicolumn{1}{|c|}{ Phytochemicals } & \multicolumn{1}{c|}{ Tests } & \multicolumn{1}{c|}{ Observation } & Inference \\
\hline \multirow{2}{*}{1.} & \multirow{2}{*}{ Alkaloids } & Iodine Test & No blue colour & - \\
\cline { 3 - 5 } & & Wagner's Test & No reddish brown precipitate & - \\
\cline { 3 - 5 } & & Dragendorff's Tests & No orange brown precipitate & - \\
\hline \multirow{2}{*}{2.} & \multirow{2}{*}{ Flavonoids } & NaOH Tests & Colourless & + \\
\cline { 3 - 5 } & & Shinoda Tests & Colourless & - \\
\hline 3. & Glycosides & Keller-Kiliani Test & No Bluish green colour & - \\
\hline 4. & Phenols & Phenol Tests & No Blue colour & + \\
\hline 5. & Saponins & Foam Test & Layer of foam & - \\
\hline 6. & Tannins & Gelatin Test & No white precipitate & + \\
\hline 7. & Carbohydrates & Molisch's test & No violet colour & - \\
\cline { 3 - 5 } & & Fehling's test & Reddish orange precipitate & - \\
\hline 8. & Proteins & Millon's test & No white precipitate & - \\
\hline
\end{tabular}

Table 2 Estimation of total flavonoid content

\begin{tabular}{|c|c|c|}
\hline S. No. & $\begin{array}{c}\text { Solvents } \rightarrow \\
\text { Bioactive compound } \downarrow\end{array}$ & $\begin{array}{c}\text { Hydroalcoholic Extract } \\
\text { (Dactylorhiza hatagirea) }\end{array}$ \\
\hline $\mathbf{1 .}$ & Total flavonoid (Quercetin equivalent (QE) $\mathrm{mg} / 100 \mathrm{mg})$ & 0.866 \\
\hline
\end{tabular}


Flavonoids compounds are secondary metabolites in plants which play an immensely important role in human health and nutrition. The HPLC chromatogram of standard quercetin and hydroalcoholic extract are shown in Fig. 1 and the values are expressed in ppm. The retention time for standard and extract was found to be $2.596 \mathrm{~min}$ and $2.42 \mathrm{~min}$ respectively. Characteristics parameters for standard quercetin was given in table 3 and results of quantitative estimation of quercetin in hydroalcoholic seed extract were given in table 4 . Percentage inhibition of $\alpha$-amylase activity by $D$. hatagirea root extract was estimated with acarbose as the positive control. D. hatagirea extract show dose dependent activity. IC 50 value of acarbose and extract was found to 35.33 and $224.45 \mu \mathrm{g} / \mathrm{ml}$ respectively Table 5 .

Table 3 Characteristics of the analytical method derived from the standard calibration curve

\begin{tabular}{|c|c|c|c|c|}
\hline Compound & $\begin{array}{c}\text { Linearity range } \\
\boldsymbol{\mu g} / \mathbf{m l}\end{array}$ & $\begin{array}{c}\text { Correlation co- } \\
\text { efficient }\end{array}$ & Slope & Intercept \\
\hline Quercetin & $5-25$ & 0.999 & 94.39 & -30.43 \\
\hline
\end{tabular}

Table 4 Quantitative estimation of quercetin in hydroalcoholic extract

\begin{tabular}{|c|c|c|c|c|}
\hline S. No. & Extract & RT & Area & \% Assay \\
\hline 1. & Dactylorhiza hatagirea & 2.42 & 546.88 & 0.1421 \\
\hline
\end{tabular}

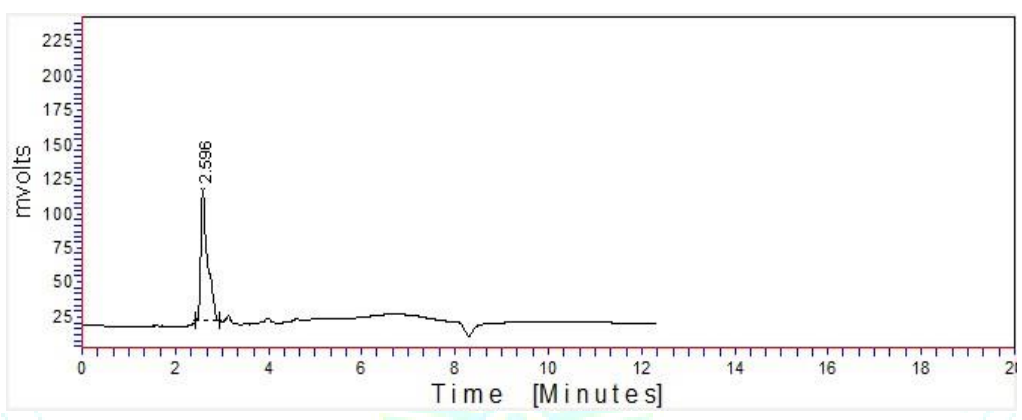

(A)

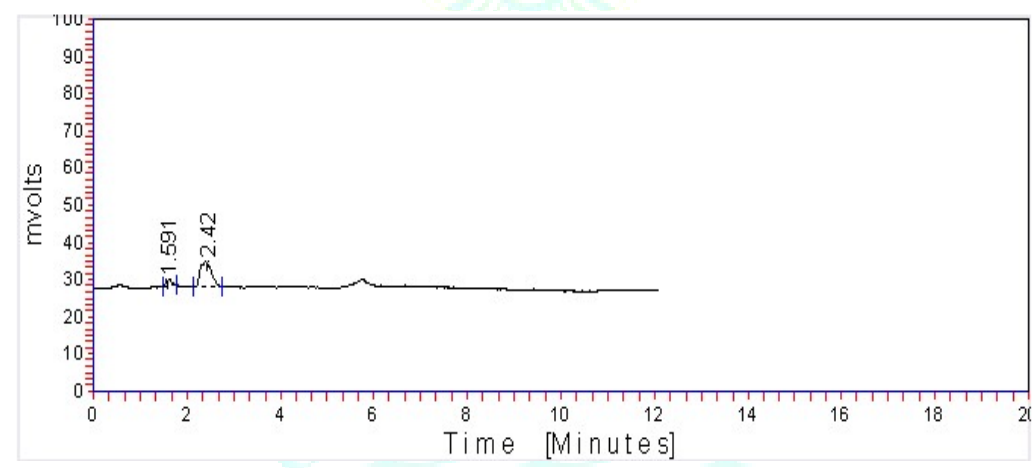

(B)

Figure 1 Chromatogram of (A) Standard Quercetin (B) Hydroalcoholic Extract of Dactylorhiza hatagirea

Table 5: In vitro antidiabetic activity of $D$. hatagirea root extract analyzed by $\alpha$-amylase inhibition assay and comparison with standard drug acarbose

\begin{tabular}{|c|c|c|c|}
\hline \multirow{2}{*}{ S. No } & \multicolumn{2}{|c|}{ Acarbose } & Dactylorhiza hatagirea \\
\cline { 2 - 4 } & Conc. & \% Inhibition & \% Inhibition \\
\hline 1. & 100 & 51.190 & 39.417 \\
\hline 2. & 200 & 70.105 & 45.502 \\
\hline 3. & 300 & 74.206 & 57.010 \\
\hline 4. & 400 & 85.185 & 66.137 \\
\hline 5. & 500 & 88.756 & 84.391 \\
\hline & $\mathbf{I C}_{\mathbf{5 0}}(\boldsymbol{\mu g} / \mathbf{m l})$ & 35.33 & 224.45 \\
\hline
\end{tabular}

It is well known fact that alloxan monohydrate induces diabetes mellitus in rats by selective necrotic action on the beta cells of pancreas leading to insulin deficiency. Insulin deficiency leads to various metabolic aberrations in animals like increased blood glucose level, increased levels of ISSN: 2250-1177 cholesterol and triglyceride and decreased protein content 26 As expected in alloxan treated rats, there was significant increase in blood glucose, cholesterol (TC) and triglyceride (TG) levels. The diabetic animals showed significant decrease in blood glucose level after 15 days treatment. 
Moreover it also decreased the levels of cholesterol (TC) and triglyceride (TG) increased by alloxan treatment. Alloxan treatment of the rats has showed the loss in body weight as compared to normal rats. However, the hydroalcoholic extract was more effective and results are comparable with that of reference drug, gliblenclamide. Hence, we can say that presence of flavonoid in the ethyl acetate fraction may be responsible for antidiabetic activity. As shown in Table 6
Blood glucose level of animals in all groups was recorded at $0,8^{\text {th }}$ and $15^{\text {th }}$ day. Progressive decrease in blood glucose level was found in all treatment groups during study. At the end of experiment Glibenclamide $600 \mu \mathrm{g} / \mathrm{kg}$, D. hatagirea 100 and $200 \mathrm{mg} / \mathrm{kg} /$ p.o. (130.50; 150.30 and 139.40) treated group blood glucose level was decrease significantly $(\mathrm{p}<0.01)$ at $15^{\text {th }}$ days, respectively.

Table 6 Effect of hydroalcoholic extract of $D$. hatagirea treatment on blood glucose $(\mathrm{mg} / \mathrm{dl})$ in normal and diabetic rats

\begin{tabular}{|c|c|lll|}
\hline Group & Treatment & \multicolumn{3}{c|}{ Blood glucose (mg/dl) } \\
\cline { 3 - 5 } & & Days 0 & Days 8 & Days 15 \\
\hline I & Normal & $90.17 \pm 5.50$ & $98.00 \pm 5.50$ & $101.30 \pm 5.50$ \\
\hline II & Diabetic Control & $270.00 \pm 10.35$ & $280.00 \pm 10.11^{\#}$ & $284.75 \pm 10.12^{\#}$ \\
\hline III & Diabetic + Dactylorhiza hatagirea & $250.00 \pm 4.50$ & $150.30 \pm 4.50^{* * *}$ & $125.20 \pm 4.50^{* * *}$ \\
\hline IV & $\begin{array}{c}\text { Diabetic + Dactylorhiza hatagirea } \\
(200 \mathrm{mg} / \mathrm{kg})\end{array}$ & $245.00 \pm 5.00$ & $139.40 \pm 5.10^{* * *}$ & $117.80 \pm 5.0^{* * *}$ \\
\hline V & $\begin{array}{c}\text { Diabetic + Glibenclamide } \\
(600 \mu \mathrm{g} / \mathrm{kg})\end{array}$ & $240.00 \pm 4.55$ & $130.50 \pm 4.50^{* * *}$ & $112.70 \pm 4.50^{* * *}$ \\
\hline
\end{tabular}

Values are expressed as mean \pm S.E.M $(n=6)$.Values are statistically significant at ${ }^{*} \mathrm{p}<0.001$ vs. normal group; ${ }^{*} P<0.001,{ }^{* *} P<$ 0.01 vs diabetic control group (Two-way ANOVA test).

As shown in Table 7 Glibenclamide $600 \mu \mathrm{g} / \mathrm{kg}$, D. hatagirea 100 and $200 \mathrm{mg} / \mathrm{kg} /$ p.o. treated group biochemical parameters like TC, TG level was decrease significantly $(\mathrm{p}<0.01)$ and total protein level was increase as compared to diabetic control group. As represented in Table 8 body weights of animals in all groups were performed at the initial and end of the study. Body weight of animals was significantly $(\mathrm{p}<0.05)$ maintained in all treatment groups (Glibenclamide $600 \mu \mathrm{g} / \mathrm{kg}, \quad D$. hatagirea 100 and 200 $\mathrm{mg} / \mathrm{kg} /$ p.o. 205, 195, 200) during study as compared to control group (160).

Table 7 Effect of hydroalcoholic extract of $D$. hatagirea treatment on biochemical parameters in normal and diabetic rats

\begin{tabular}{|c|c|c|c|c|}
\hline Group & Treatment & $\begin{array}{c}\text { TC } \\
\mathbf{( m g} / \mathbf{d L})\end{array}$ & $\begin{array}{c}\text { TG } \\
\mathbf{( m g} / \mathbf{d L})\end{array}$ & $\begin{array}{c}\text { Total } \\
\text { protein(g/dl) }\end{array}$ \\
\hline I & Normal & $90.00 \pm 5.00$ & $80.00 \pm 5.00$ & $8.00 \pm 0.45$ \\
\hline II & Diabetic Control & $180.0 \pm 6.00$ & $153.0 \pm 6.00$ & $5.00 \pm 0.50$ \\
\hline III & $\begin{array}{c}\text { Diabetic }+ \text { Dactylorhiza hatagirea } \\
(100 \mathrm{mg} / \mathrm{kg})\end{array}$ & $109.6 \pm 5.55^{* *}$ & $95.50 \pm 5.50^{*}$ & $7.90 \pm 0.30^{* *}$ \\
\hline IV & $\begin{array}{c}\text { Diabetic + Dactylorhiza hatagirea } \\
(200 \mathrm{mg} / \mathrm{kg})\end{array}$ & $105.1 \pm 5.10^{* *}$ & $92.50 \pm 5.56^{*}$ & $8.35 \pm 0.45^{* *}$ \\
\hline $\mathrm{V}$ & $\begin{array}{c}\text { Diabetic }+ \text { Glibenclamide } \\
(600 \mu \mathrm{g} / \mathrm{kg})\end{array}$ & $101.1 \pm 5.10^{* *}$ & $89.20 \pm 5.22^{*}$ & $8.75 \pm 0.25^{* *}$ \\
\hline
\end{tabular}

Table 8 Effects of hydroalcoholic extract of $D$. hatagirea on body weight

\begin{tabular}{|c|c|c|c|}
\hline Group & Treatment & $\begin{array}{r}\text { Initial weight } \\
\text { (gm) }\end{array}$ & $\begin{array}{r}\text { Final weight } \\
\text { (gm) }\end{array}$ \\
\hline $\mathrm{I}$ & Normal & $160.00 \pm 9.00$ & $180.10 \pm 9.06$ \\
\hline II & Diabetic Control & $170.00 \pm 8.40$ & $160.00 \pm 8.40$ \\
\hline III & $\begin{array}{c}\text { Diabetic }+ \text { Dactylorhiza hatagirea } \\
(100 \mathrm{mg} / \mathrm{kg})\end{array}$ & $165.00 \pm 10.00$ & $195.00 \pm 7.32$ \\
\hline IV & $\begin{array}{c}\text { Diabetic + Dactylorhiza hatagirea } \\
(200 \mathrm{mg} / \mathrm{kg})\end{array}$ & $165.00 \pm 9.20$ & $200.00 \pm 8.42$ \\
\hline $\mathrm{V}$ & $\begin{array}{c}\text { Diabetic + Glibenclamide } \\
(600 \mu \mathrm{g} / \mathrm{kg}) \\
\end{array}$ & $160.00 \pm 7.80$ & $205.00 \pm 8.16$ \\
\hline
\end{tabular}

\section{CONCLUSION}

From the present study, it is concluded that $D$. hatagirea may be useful in treating diabetes mellitus with no visible signs or symptoms of toxicity in normal rats indicating a high margin of safety. The hydroalcoholic extracts of $D$. hatagirea have indicated high level of anti-diabetic activity. The extracts exhibited anti-hyperglycemic activity comparable to that of a standard anti-diabetic drug, glibenclamide. The traditional use of $D$. hatagirea to treat diabetes is supported by laboratory results from this study, suggesting a need to isolate and evaluate active constituents responsible for the exhibited biological activity. 


\section{REFERENCES}

1. Davis D. Insulin, oral hypoglycemic agents and the pharmacology of the endocrine pancreas in The Pharmacological Basis of Therapeutics, L. Brunton, J. Lazo, and K. Parker, Eds., p. 1613, McGraw-Hill, New York, NY, USA, 2006.

2. DewanjeeS, Das $\mathrm{AK}$, Sahu $\mathrm{R}$, et al. Antidiabetic activity of Diospyros peregrina fruit: effect on hyperglycemia, hyperlipidemia and augmented oxidative stress in experimental type 2 diabetes. Food Chem Toxicol 2009; 47; 2679-2685.

3. Lin Y, Sun Z. Current views on type 2 diabetes. J Endocrinol 2010; 204: 1-11.

4. Gray RS, Fabsitz RR, Cowan LD, et al. Risk factor clustering in the insulin resistance syndrome. The strong heart study. American J Epidemiol 1998; 148: 869-878.

5. Oranje WA, Wolffenbuttel BHR. Lipid peroxidation and atherosclerosis in type II diabetes. J Laborat Clin Med 1999; 134: 19-32.

6. Mukherjee PK, Maiti Mukherjee KK, et al. Leads from Indian medicinal plants with hypoglycemic potentials. J Ethnopharmacol 2006; 106: 1-28.

7. Tiwari AK, Rao JM. Diabetes mellitus and multiple therapeutic approaches of phytochemicals: present status and future prospects. Curr Sci 2002; 83 30-38.

8. Badola HK, et al. The Himalayas of India: a treasury of medicinal plants under siege, Biodiversity 2003; 4: 3-13.

9. Dhar U, et al. Alpine Flora of Kashmir Himalaya, Scientific Publishers, Jodhpur, India, 1983.

10. Hajra PK, et al. Plant Wealth of Nanda Devi Biosphere Reserve, Botanical Survey of India, Calcutta, India, 1995.

11. Bhatt A, et al. Dactylorhiza hatagirea (D. Don) Soo-a west Himalayan orchid in peril. Curr Sci 2005; 89: 10-612.

12. Chauhan RS, et al. A note on Dactylorhiza hatagirea (D. Don) Soo, The McAllen Int Orchid Soc J 2008; 9: 8-12.

13. Aswal BS, et al. Flora of Lahaul-Spiti, Bishen Singh and Mahendra Pal Singh, Dehradun, India, 1994.

14. Pant $S$, et al. Dactylorhiza hatagirea: a high value medicinal orchid. J Med Plants Res 2012;6: 3522-3524.
15. Dutta IC, et al. Antibacterial Activities of Some Traditional Used Medicinal Plants of Daman, Nepal. Pokhara, Nepal: TU, IOF, and ComForm 2007.

16. Baral SR, et al. A Compendium of Medicinal Plants in Nepal. Katmandu, Nepal: Central Bureau of Statistics, Government of Nepal 2006.

17. Ballabh B, et al. Herbal products fromhigh altitude plants of Ladakh Himalaya. Curr Sci 2007; 92: 1664-1665.

18. Khandelwal KR. Practical pharmacognosy technique and experiments. 23rd Ed. Nirali Prakashan; 2005.

19. Kokate CK. Practical pharmacognosy. $4^{\text {th }}$ Ed. Vallabh Prakashan; 1994.

20. Olufunmiso 00, Afolayan AJ. Phenolic content and antioxidant property of the bark extract of Ziziphus mucronata willd. Subsp. mucronata willd, BMC Comp Alter Med 2011; 11:130.

21. Guideline Document on Acute oral Toxicity Testing, Series on Testing and Assessment No. 423. Paris: Organization for Economic Co-Operation and Development, OECD Environment, Health and Safety Publications; 1996. Available from: http//www.oecd.org/ehs.

22. Jonsson M, Jestoi M, Nathanail AV, et al. Application of OECD Guideline 423 in assessing the acute oral toxicity of moniliformin. Food Chem Toxicol 2013; 53: 27-32.

23. PareekH, Sharma S, Khajja BS, et al. Evaluation of hypoglycemic and anti-hyperglycemic potential of Tridax procumbens (Linn.) BMC Comp Alter Med 2009; 9:48

24. Adeneye AA, Ajagbonna OP, Ayodele OW. Hypoglycemic \& antidiabetic activities on the stem bark aqueous \& ethano extracts of Musanga cecropioides in normal \& alloxan induced diabetic rats. Fitoterapia 2007; 78:502-505.

25. Roy S, Sehgal R, Padhy BM, Kumar VL. Antioxidant and protective effect of latex of Calotropis procera against alloxan induced diabetic rats. J Ethnopharmacol 2005; 102: 470-3.

26. Dhanabal SP, Mohan Maruga Raja MK, Ramanathan M, Suresh B. Hypoglycemic activity of Nymphaea stellata leaves ethanolic extract in alloxan induced diabetic rats. Fitoterapia 2007; 78 288-291. 